\title{
Toward a Simplified Arc Impingement Model in a Direct-Current Electric Arc Furnace
}

\author{
Mohamad Al-Nasser ${ }^{1}$, Abdellah Kharicha ${ }^{1, *}{ }^{+}$, Hadi Barati ${ }^{1,2}$, Christoph Pichler ${ }^{3}{ }^{\mathbb{D}}$, Gernot Hackl ${ }^{3}$, \\ Markus Gruber ${ }^{3}$, Anton Ishmurzin ${ }^{3}$, Christian Red1 ${ }^{4}$, Menghuai $\mathrm{Wu}^{2}{ }^{2}$ and Andreas Ludwig ${ }^{2}$
}

1 Christian Doppler Laboratory for Metallurgical Applications of Magnetohydrodynamics, Franz-Josef Street 18, 8700 Leoben, Austria; Mohamad.al-nasser@unileoben.ac.at (M.A.-N.); Hadi.Barati@unileoben.ac.at (H.B.)

2 Chair for Modeling and Simulation of Metallurgical Processes, Department of Metallurgy, Montanuniversität, Franz-Josef Street 18, 8700 Leoben, Austria; menghuai.wu@unileoben.ac.at (M.W.); ludwig@unileoben.ac.at (A.L.)

3 Department of Modelling and Simulation, RHI Magnesita, Magnesitstrasse 2, 8700 Leoben, Austria; Christoph.Pichler@RHIMagnesita.com (C.P.); Gernot.Hackl@RHIMagnesita.com (G.H.); Markus.Gruber@RHIMagnesita.com (M.G.); Anton.Ishmurzin@RHIMagnesita.com (A.I.)

4 INTECO Melting and Casting Technologies GmbH, Wienerstrasse 25, 8600 Bruck a.d. Mur, Austria; Christian.Redl@inteco.at

* Correspondence: Abdellah.kharicha@unileoben.ac.at

\section{check for} updates

Citation: Al-Nasser, M.; Kharicha, A.; Barati, H.; Pichler, C.; Hackl, G.; Gruber, M.; Ishmurzin, A.; Redl, C.; Wu, M.; Ludwig, A. Toward a Simplified Arc Impingement Model in a Direct-Current Electric Arc Furnace. Metals 2021, 11, 1482. https://doi.org/10.3390/ met11091482

Academic Editors: Thomas Echterhof, Ko-Ichiro Ohno and Ville-Valtteri Visuri

Received: 15 July 2021

Accepted: 10 September 2021

Published: 17 September 2021

Publisher's Note: MDPI stays neutral with regard to jurisdictional claims in published maps and institutional affiliations.

Copyright: (c) 2021 by the authors. Licensee MDPI, Basel, Switzerland. This article is an open access article distributed under the terms and conditions of the Creative Commons Attribution (CC BY) license (https:// creativecommons.org/licenses/by/ $4.0 /)$.
Abstract: A 2D axisymmetric two-phase model was developed to study the effect of an arc impingement on the liquid metal inside an electric arc furnace. In addition to the arc flow dynamics, the model covered the heat transfer and magneto hydrodynamics of the arc and the liquid metal. Through a parametric study, three different parameters were considered to predict the most important factors affecting the arc and overall behaviour of the process: the arc gap, the density of the gas, and the total electric current. Understanding the effect of these parameters can show the key factors altering the arc dynamics. The study showed that the total applied current was the most important parameter that influenced the impingement depth and mixing of the liquid metal. The depth of the impingement and strength of the mixing of the liquid bath were directly proportional to the current applied in the furnace. The initial arc gap distance was found to be crucial for sustaining a continuous and stable arc. The value of the gas density was very important for the velocity profile; however, it had no significant effect on the impingement depth. This showed that a constant density could be used instead of a varying gas density with temperature to increase the computational efficiency. The study assessed the effects of the aforementioned factors on the arc impingement depth, velocity magnitude, and arc stability. The conclusions acquired and challenges are also presented.

Keywords: direct current; electric arc furnace; arc impingement; arc gap; gas density; electric arc; magneto hydrodynamics; computational fluid dynamics

\section{Introduction}

The first use of an electric arc furnace (EAF) was in the 19th century. Although a direct current (DC) in an EAF was first used in the late 1800s, the major development and industrial use was focused on alternating current (AC) furnaces. This was driven by the better efficiency and power transmission of AC power. In the past three decades, the DC-EAF has again been highly utilised in the metallurgical industry through a variety of applications such as steel scrap melting and smelting processes [1]. The shift toward DC furnaces is because they are now believed to have a better power efficiency, less electrode consumption, and a lower level of noise. DC arcs are also more stable by nature compared with AC arcs. As a result of the increasing demand for DC arc furnaces in industry, further improvements in their design and a better understanding of the method of operations are required. A typical configuration of the DC-EAF entails a large liquid metal bath cylinder 
with refractory walls covered by a conical roof cooled by water. The cathode electrode is mounted on the top of the metal scrap bath separated by the arc gap. A flat anode of graphite is situated directly under the metal bath in direct contact, as shown in Figure 1.

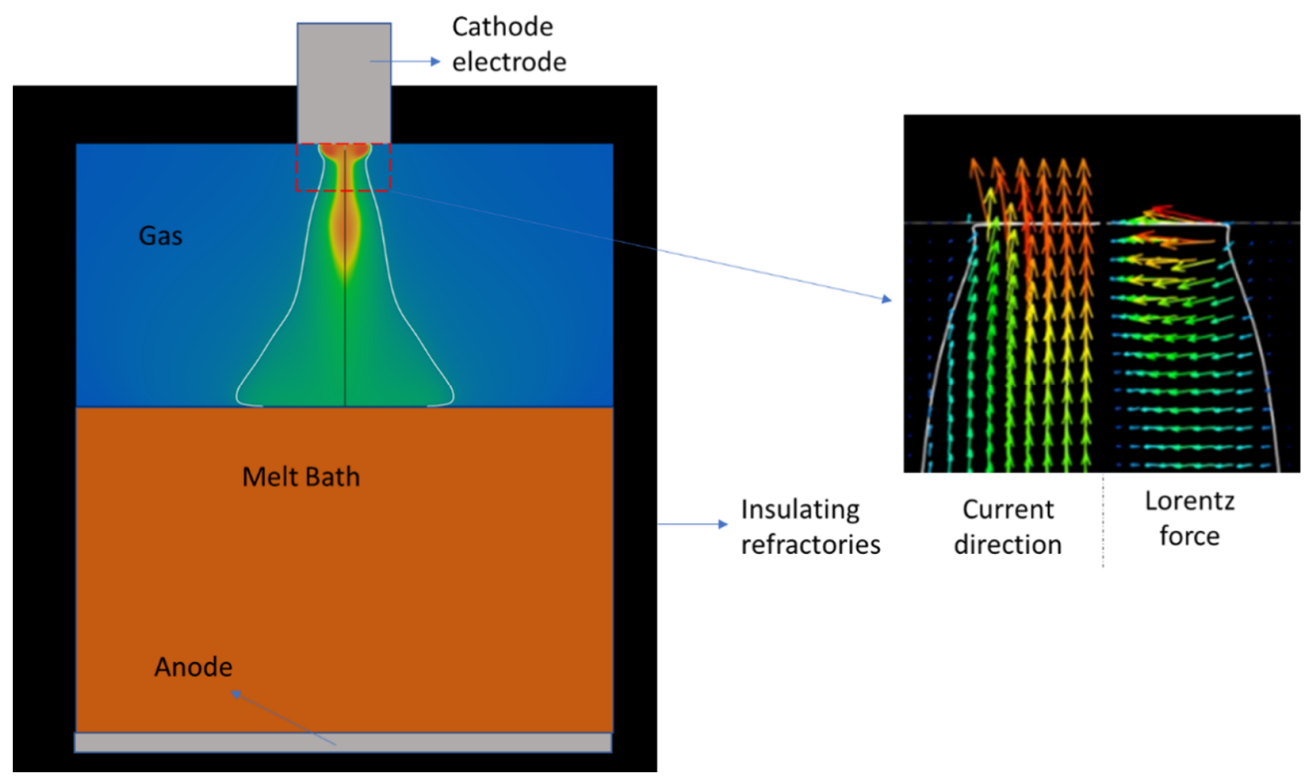

Figure 1. Electric arc furnace schematic.

The arc propagates in this gap providing the thermal and mechanical drive for the furnace.

The arc converts the electric energy supplied by the circuit into thermal and mechanical energy. This arises due to the electrical breakdown of gas as a result of a high potential difference in the arc gap. At high temperatures (5000-7000 K), thermal dissociation is accomplished rendering neutral molecules of gas into conductive ions and electrons [2]. The gas is transformed into thermal plasma that is electrically conductive. The current flows through the arc interacting with its magnetic field. This interaction results in the Lorentz force acting radially inwards along the arc, constricting the arc diameter. At the cathode spot, the Lorentz force acts in an inclined direction toward the cathode spot thus sucking the gas inside, as shown in Figure 1. A powerful jet is created; it is restrained near the cathode spot and then expands gradually as it propagates downwards. Experimental measurements [3] predicted that the speed of the gas inside the jet can reach the orders of $\mathrm{km} / \mathrm{s}$. This is capable of creating a thrust that disturbs and penetrates through the surface of the slag and liquid metal, creating a cavity and causing significant splashing that alters the nature and behaviour of the arc. As the electric current flows through the gas arc gap, a high amount of thermal energy is released due to resistive heating that prevents the extinction of the arc as simultaneous heat is released through radiation and convection into the metal bath. This ensures the delivery of the high thermal energy into the metal avoiding any undesired solidification. The impingement also creates a mechanical drive to recirculate and stir the liquid metal.

Historically, the development of arc furnace technology was purely experimental (trial and error). The first mathematical studies were performed on the arc region by Ushio et al. [4] and Szekely et al. [2]. In their work, they represented the thermal and electromagnetic fields through solving the arc region by turbulent Navier-Stokes equations for flow. Alexis et al. [5] developed a mathematical model that predicted the fluid flow and electromagnetic field in addition to the thermal field effect on the liquid metal bath. Although these studies focused on the arc thermal and electromagnetic fields in detail, the major drawback was the lack of momentum coupling with the liquid metal bath. The effect of the electromagnetic fields on the liquid metal bath was covered Szekely et al. [3] 
where the thermal effect of the arc on the metal bath without an electromagnetic force was studied. Ramírez et al. [6] performed a simulation to analyse the heat transfer from the arc and electromagnetic effects on the flow inside the fluid bath. The mixing due to the electro-vortex flow drastically affected the distribution of heat from the arc and the durability of the refractories. Kazak [7] studied the effect of the Lorentz force and thermal stresses on the walls of the furnace.

Reynolds [8] analysed the effect of the arc impingement on the liquid bath in a multiphase simulation considering the arc as a gas jet and neglecting the electromagnetic nature and forces. Klementyeva et al. [9] conducted experimental measurements to examine the effect of the arc on the free surface of the liquid metal. A study conducted by Reynolds [10] simulated a lab scale arc impinging the liquid bath of two immiscible phases for different values of the current and arc gap. Adib et al. [11] studied the effect of a high-speed air jet impinging the liquid surface using a VOF formulation and measured the interface deformation and cavity depth. Most of the works reported in the literature have studied one aspect of the DC-EAF but very few of them have introduced the full coupling of the plasma arc and liquid metal interaction. This may be due to the limitation in the computational power and the complexity of the realisation of the arc-liquid interaction.

This paper introduces a study of a multiphase arc simulation. The thermal and electromagnetic fields of the arc are predicted through solving the momentum and induction equations. The liquid metal bath is fully considered with its thermal and electrical properties. This two-way coupling of the arc and free surface of the liquid enable us to capture the arc impingement and the thermal and electromagnetic effect on both the arc and molten metal in a DC-EAF on an industrial scale. The paper relies on several data and parameters from the literature, which was necessary to build upon-instead of spending effort in exploring - what had already been previously achieved. This paper introduces several new advancements to boost the arc modelling especially coupled with liquid bath beneath. Previous studies have mostly focused on the simulation of a single-phase electric arc with a solid surface of a metal bath. A few studies have included the consideration of a liquid metal bath, such as the heat transfer effect, but there has only been one with full coupling and an interaction between the arc and the liquid bath [10] with much smaller current values. This paper assesses the effect of the gas density value and how this assumption helps to reduce the required computational power to achieve the same real-time simulation without greatly affecting the accuracy. The study also aims to explore the major parameters that affect the impingement depth and size.

\section{Modelling}

The physical arrangement considered in this study covered the micro-environment around the arc rather than the whole furnace geometry for the sake of practical reasons. The configuration consisted of a 2D axisymmetric geometry covering a part of the electrode, the arc gap, and the liquid metal bath. A two-phase flow situation was considered: the gas phase and the liquid metal. The slag layer was not considered. The setup is shown in Figure 2, manifesting the uniform mesh generated for the domain. The numbers in Figure 2 from 1 to 6 indicate the boundary conditions: (1) cathode spot; (2) electrode side; (3) gas top boundary; (4) domain side; (5) metal bath bottom (anode); and (6) the axis of symmetry.

\subsection{Governing Equations}

The flow was considered to be multiphase where the two fluids were the gas and the liquid metal. The Volume of Fluid ( $\mathrm{VoF})$ multiphase model was adopted to simulate the flow in the domain. The continuity, momentum, energy, and induction equations were solved. 


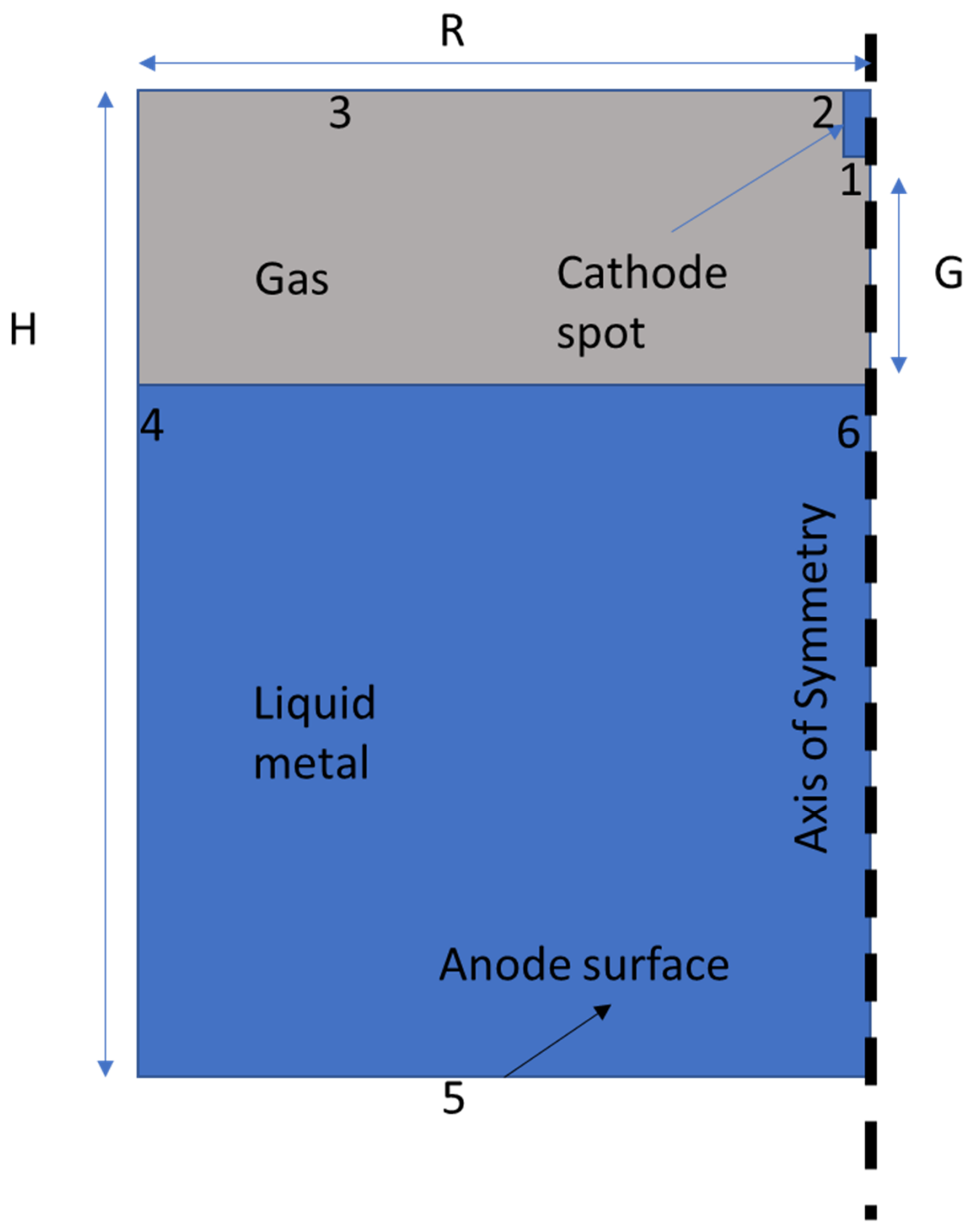

Figure 2. Geometry of the domain: $R=0.8, H=1 \mathrm{~m}$. The electrode length was 0.04 and the radius was 0.008 ; the $\operatorname{arc}$ gap $(G)$ was 0.25 , and the metal bath depth was initially $0.71 \mathrm{~m}$.

The case was simulated using ANSYS FLUENT ${ }^{\circledR}$ version 14.5 [12]. The equations are described below. The electromagnetic variables were calculated through coupling user-defined functions (UDFs) with fluent solvers.

Continuity:

$$
\frac{\partial \rho}{\partial t}+\nabla(\rho \vec{U})=0
$$

Here, $\rho$ is the density and $U$ is the velocity vector field.

Momentum:

$$
\frac{\partial(\rho \vec{U})}{\partial t}+\nabla \cdot(\rho \vec{U} \vec{U})=-\nabla p+\nabla \cdot(\mu \nabla \vec{U})+\rho g+F+\frac{1}{\mu_{0}}(\vec{J} \times \vec{B})
$$


where $p, \mu, g, F, \mu_{0}, J$, and $B$ stand for the pressure, viscosity, gravitational acceleration, external forces, vacuum permeability, current density, and magnetic field, respectively.

Enthalpy:

$$
\frac{\partial}{\partial t}\left(\rho c_{p} T\right)+\nabla \cdot\left(\rho c_{p} \vec{U} T\right)=\nabla \cdot(k \nabla T)+J_{\text {heat }}+\operatorname{Rad}_{\text {loss }}
$$

where $c_{p}$ is the specific heat, $T$ is the temperature, and $K$ is the thermal conductivity. Jheat is the joule heating $\frac{\left\|J^{2}\right\|}{\sigma}, J$ is the current density, and $\sigma$ is the electrical conductivity. $\operatorname{Rad}_{l o}$. is the radiation loss. The radiation heat loss was based on experimental measurements [12] for air at $1 \mathrm{~atm}$ pressure.

Induction equation:

$$
\frac{\partial B_{\theta}}{\partial t}+\nabla \cdot\left(\vec{u} B_{\theta}\right)=\nabla\left(\frac{1}{\sigma \mu_{0}} \nabla B_{\theta}\right)+\frac{\partial}{\partial r}\left(\frac{1}{\sigma \mu_{0} r}\right) B_{\theta}
$$

In order to simulate the arc and its interaction with the liquid bath, certain assumptions were adopted due to the high complexities. The flow inside the arc was considered to be always in a local thermal equilibrium. This enabled the use of electrical conductivity solely dependent on the temperature. Electrical conductivity is very low (almost zero) at an atmospheric temperature. It increased to a relatively low order of $1 \mathrm{~S} / \mathrm{m}$ at a metal bath temperature of $1800 \mathrm{~K}$ and increased to reach a high conductivity of $3000 \mathrm{~S} / \mathrm{m}$ inside the arc where the temperature exceeded $10,000 \mathrm{~K}$ [13]. The electrical conductivity of the liquid metal was constant and significantly larger than $80,000 \mathrm{~S} / \mathrm{m}$. This created a huge gradient at the interface especially away from the high temperature regions. A small volume fraction of liquid metals can induce a large increase in electrical conductivity. To solve this sudden increase numerically, a harmonic function was implemented:

$$
\sigma_{\text {int }}=\frac{\sigma_{g} \sigma_{m}}{\alpha_{g} \sigma_{g}+\left(1-\alpha_{g}\right) \sigma_{m}}
$$

where $\sigma$ and $\alpha$ stand for the electrical conductivity and volume fraction, respectively, and $g$ denotes gas and $m$ denotes metal.

Metal properties are assumed to be constant. Gas properties, except density, are temperature-dependent [13]. The dependency of the density induces strong numerical difficulties. This is why we considered the density to be constant and independent of the temperature. This study aimed to predict the overall arc behaviour as a result of an impingement rather than the exact detailed behaviour of the arc. To validate this assumption, a parametric study on the density of the gas was carried out. The assumption of a constant density led to a better stability of the simulation and thus the calculation of the time step could be increased. Other properties, such as the specific heat and dynamic viscosity of the gas, are temperature-dependent, based on Boulos [13]. The implementation of a radiation model was added to the energy equation that considered the liquid metal bulk and solid surfaces to be opaque while the liquid surface had a temperature of $1800 \mathrm{~K}$. The radiation inside the domain was calculated in each cell based on this assumption. The properties of the liquid metal are shown in Table 1.

Table 1. Liquid metal properties.

\begin{tabular}{ccccc}
\hline Density & Specific Heat & $\begin{array}{c}\text { Thermal } \\
\text { Conductivity }\end{array}$ & Viscosity & $\begin{array}{c}\text { Electrical } \\
\text { Conductivity }\end{array}$ \\
\hline $7000 \mathrm{~kg} / \mathrm{m}^{3}$ & $800 \mathrm{~J} / \mathrm{kg}$ & $40 \mathrm{~W} / \mathrm{mK}$ & $0.006 \mathrm{~Pa} . \mathrm{s}$ & $800,000 \mathrm{~S}$ \\
\hline
\end{tabular}




\subsection{Simulation Settings}

The top boundary of the domain was considered to be cooled by water, the surface temperature was $500 \mathrm{~K}$ and the temperature of the water was $300 \mathrm{~K}$. All other boundaries were considered to be thermally adiabatic walls. The temperature of the cathode spot was set to be constant at $4000 \mathrm{~K} \mathrm{[14]} \mathrm{and} \mathrm{the} \mathrm{metal} \mathrm{bath} \mathrm{was} \mathrm{considered} \mathrm{to} \mathrm{be} \mathrm{initially} \mathrm{in} \mathrm{a} \mathrm{liquid}$ phase with a uniform temperature of $1800 \mathrm{~K}$. The total current was supplied at the top of the electrode and the cathode spot had a constant current density of $4.4 \times 10^{7} \mathrm{~A} / \mathrm{m}^{2}$ [15]. The cathode spot area was calculated by dividing the total current by the current density and the electrode radius was set to be equal to the cathode spot for simplicity. No external magnetic field was considered.

The initial temperature distribution inside the arc environment was based on the thermal distribution of an arc with a $0.25 \mathrm{~cm}$ arc gap [6]. It is important to point out that the arc gap defined the vertical distance between the cathode spot and the initial flat surface of the conducting liquid. This was different from the actual arc length presented at the end of this paper. The actual arc length was the length of the arc connecting the cathode spot and the anode spot at the impinged liquid surface. Figure 3 shows the difference between actual arc length and arc gap. The lower part was liquid metal at $1800 \mathrm{~K}$. The boundary conditions for the induction equation are presented in Table 2.

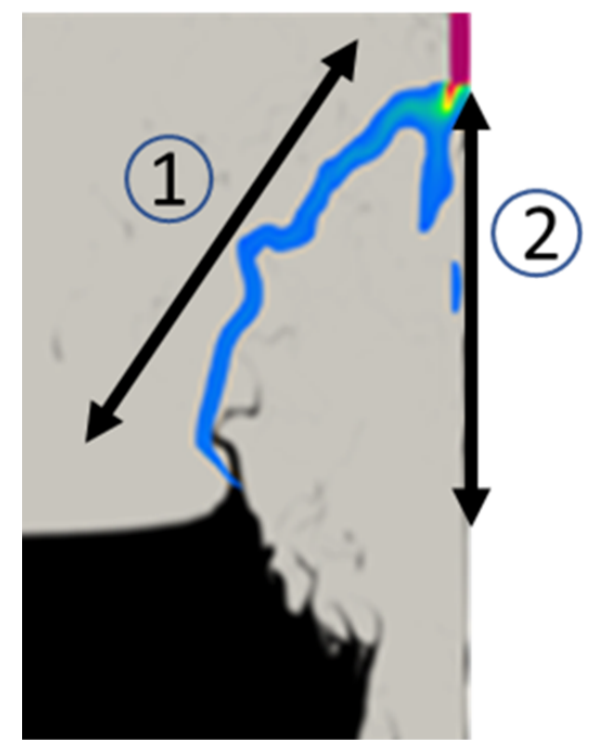

Figure 3. Electric arc during the impingement of the liquid metal: (1) actual arc length; (2) arc gap.

Table 2. Induction equation boundary conditions for the domain.

\begin{tabular}{cccc}
\hline Boundary & $\begin{array}{c}\text { Flow Boundary } \\
\text { Conditions }\end{array}$ & $\begin{array}{c}\text { Thermal Boundary } \\
\text { Conditions }\end{array}$ & $\begin{array}{c}\text { Induction Equation } \\
\text { Boundary Conditions }\end{array}$ \\
\hline 1. Electrode Bottom & $\vec{U}=0$ & $T=4000 \mathrm{~K}$ & $\frac{\partial B_{\theta}}{\partial z}=0$ \\
2. Electrode Side & $\vec{U}=0$ & $\frac{\partial T}{\partial r}=0$ & $B_{\theta}=\frac{I_{0} \mu_{0} r}{2 \pi R_{c}{ }^{2}}$ \\
3. Gas Top & $\frac{\partial U_{r}}{\partial z}=0, U_{z}=0$ & $T=500 \mathrm{~K}$ & $B_{\theta}=\frac{I_{0} \mu_{0}}{2 \pi r}$ \\
4. Gas and Melt Side & $\vec{U}=0$ & $\frac{\partial T}{\partial r}=0$ & $B_{\theta}=\frac{I_{0} \mu_{0}}{2 \pi r}$ \\
5. Metal Bath Bottom & $\vec{U}=0$ & $\frac{\partial T}{\partial z}=0$ & $\frac{\partial B_{\theta}}{\partial z}=0$ \\
(Anode) & $\frac{\partial U_{z}}{\partial r}=0, U_{r}=o$ & $\frac{\partial T}{\partial r}=0$ & $B_{\theta}=0$ \\
6. Axis of Symmetry & & &
\end{tabular}


The equations were solved using the finite volume method. The simulations were completed in a transient mode for a relatively significant real flow time to achieve the arc impingement effects. As indicated, several simulations were performed to assess the effects of the different parameters on the arc impingement and the stability of the arc. The main variables covered in this study were the arc gap distance, the density of the plasma, and the global current.

The mesh used in the study was a quadratic uniform mesh composed of 200,000 elements over the domain. The cell face size was $2 \mathrm{~mm}$. A mesh dependency test was performed to ensure that the results were not dependent on the mesh size. A total of 4 different meshes were tested with cell sides of $4 \mathrm{~mm}, 2.66 \mathrm{~mm}, 2 \mathrm{~mm}$, and $1 \mathrm{~mm}$, which resulted in mesh sizes of 50,000, 125,000, 200,000, and 400,000, respectively. The maximum velocity of the arc before hitting the liquid surface for the different mesh sizes is shown in Figure 4 . The depth of the first impingement wave was also plotted, which showed almost no difference over the 4 meshes (Figure 5). This showed that for mesh sizes larger than 200,000 elements, the results were not dependent on the mesh size.

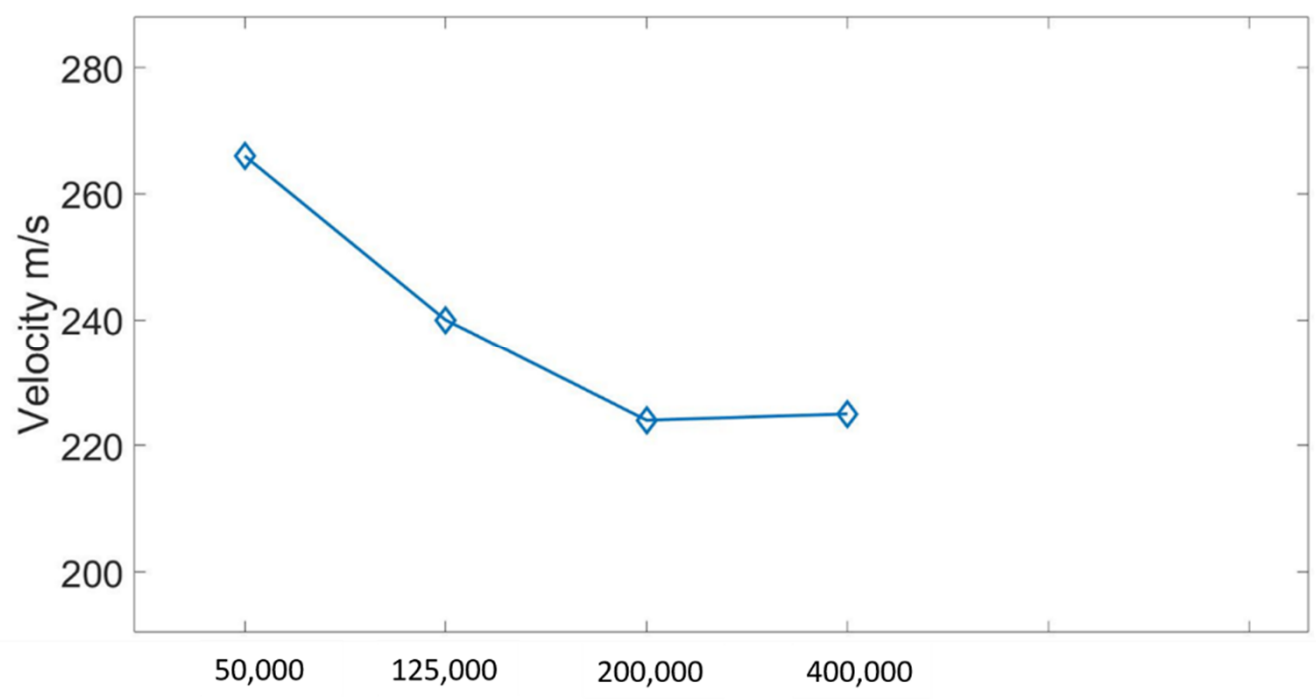

Figure 4. Velocity magnitude as a function of the mesh size.

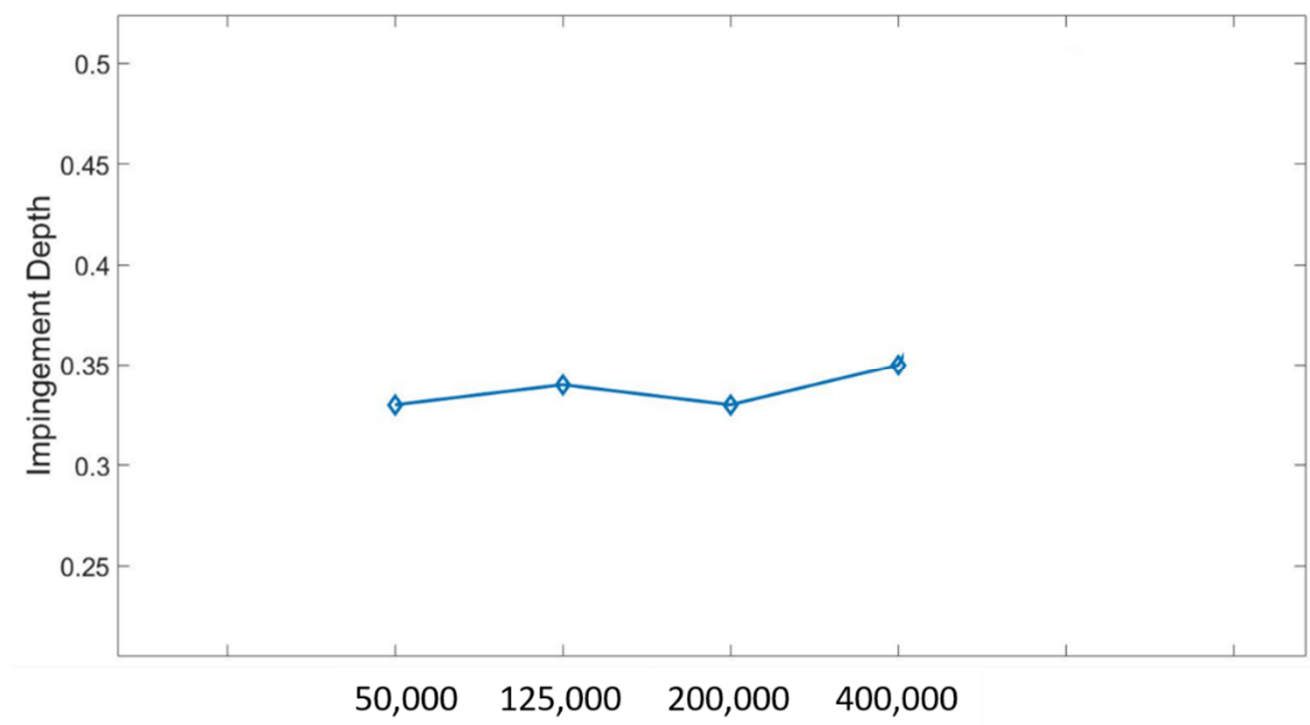

Figure 5. Impingement depth as a function of the mesh size. 


\section{Results and Discussion}

\subsection{Reference Case}

For an EAF, the arc gap is often set between $0.1 \mathrm{~m}$ and $0.5 \mathrm{~m} \mathrm{[16];} \mathrm{here,} \mathrm{the} \mathrm{arc} \mathrm{gap} \mathrm{of}$ choice was $0.25 \mathrm{~m}$ as the reference configuration (control case). For the total current, the initial current was equal to $10 \mathrm{kA}$ and the density was constant and equal to $1 \mathrm{~kg} / \mathrm{m}^{3}$. The time step was $10^{-5} \mathrm{~s}$.

Figure 6 depicts the initial state of the domain. The jet emerging from the cathode spot shows the initial current distribution inside the gas before diffusing into the flat surface of the conducting liquid. The yellow contour shows the zoomed area shown in the arc impingement simulation for the gap and density parametric study.

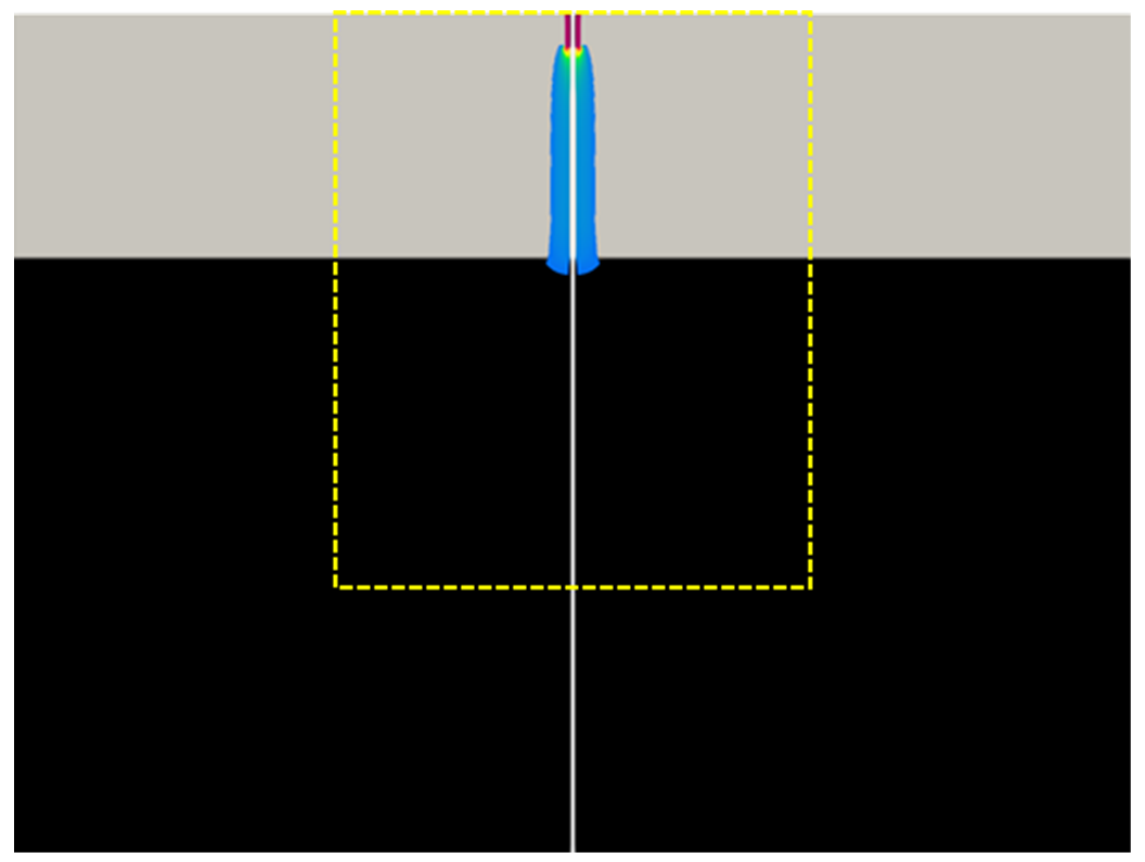

Figure 6. Simulation domain. The yellow frame shows the zoomed domain for a better visual depiction.

Once the arc jet reached the liquid surface, an impingement wave formed pushing the liquid metal downwards and displacing it away from the jet path (Figure 7). Figure 7 illustrates the arc impingement for the reference model during different time snaps. The left half shows the electric current lines ( $J$ is the current density) and the right half shows the velocity magnitude of the gas ( $U$ is the velocity magnitude). The liquid metal is shown in black. This applies for all the following figures that display the arc impingement. The wave initially propagated vertically and then created a wide cavity. The arc jet pushed the liquid metal droplets upwards, as shown in the $0.286 \mathrm{~s}$ image in Figure 7 . The cavity expanded and shrank continuously and a wave travelled along the surface. The splashing of droplets appeared to be continuous and the droplets were transported far away from the arc impingement location. A few of the droplets recirculated inside the arc region. The motion of the arc was instantaneously compared with the aerodynamics and motions of the liquid metal. The arc tended to choose the shortest distance in the gas to reach the liquid metal (Figure 7,0.8 s). When the shortest distance between the electrode and the liquid metal was different from the original path position (near the axis) the arc deviated, as shown in Figure 7,0.8 s. 


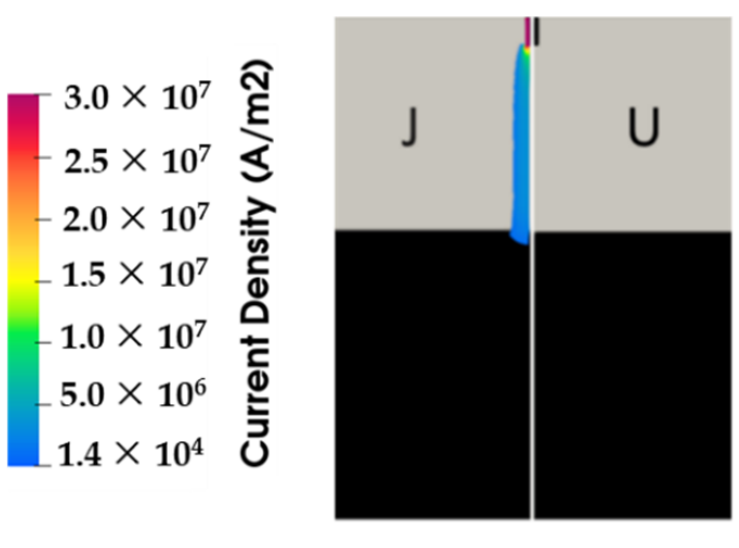

$0 \mathrm{~s}$

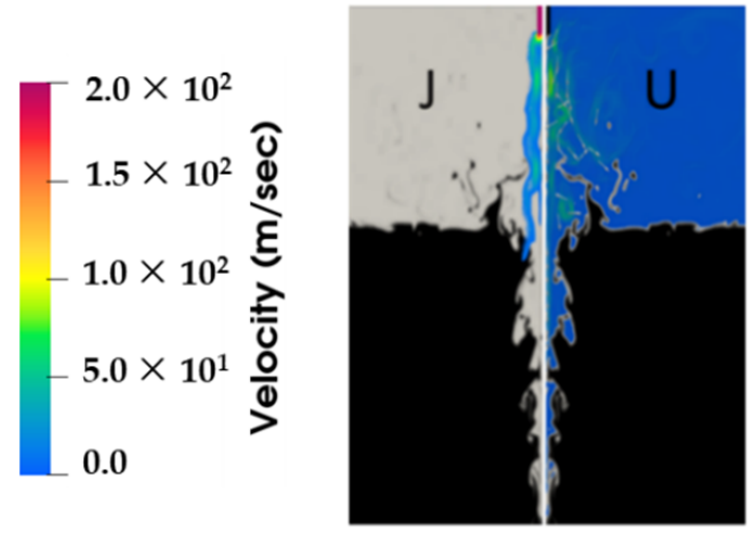

$0.286 \mathrm{~s}$

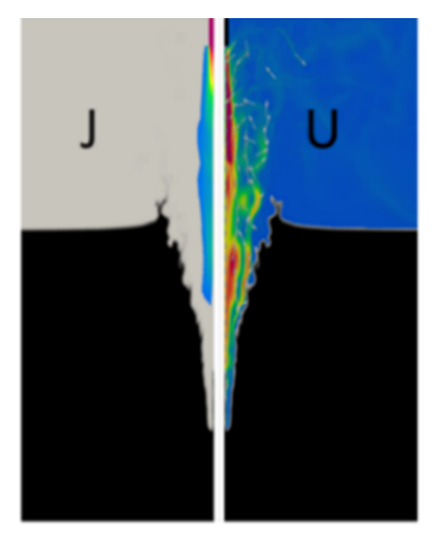

$0.166 \mathrm{~s}$

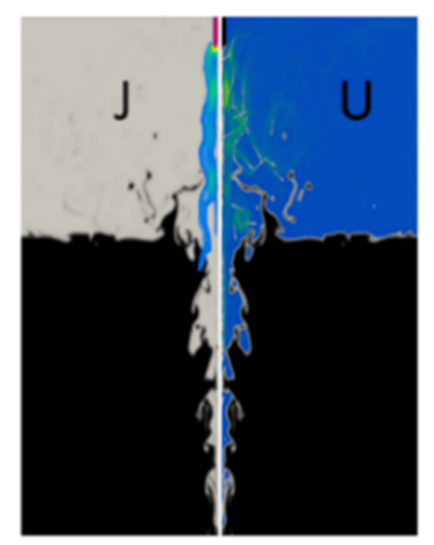

$0.586 \mathrm{~s}$

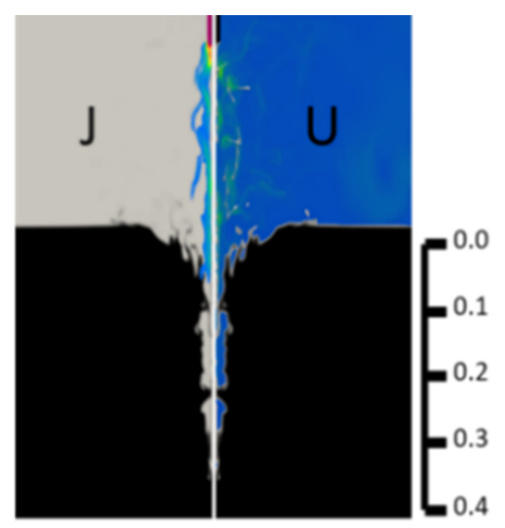

$0.194 \mathrm{~s}$

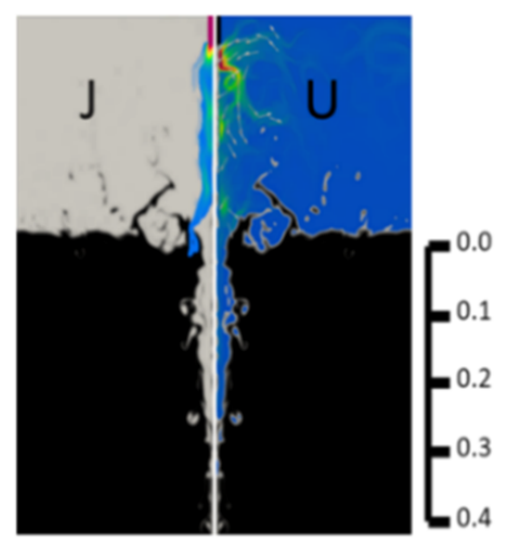

$0.8 \mathrm{~s}$

Figure 7. Arc impingement arc gap of $2.5 \times 10^{-1} \mathrm{~m}$.

\subsection{Effect of the Arc Gap}

Apart from the reference case, two other arc gaps of $0.2 \mathrm{~m}$ and $0.3 \mathrm{~m}$ were also considered. For the gap of $0.2 \mathrm{~m}$, the splashing and impingement width was larger compared with the arc impingement of the $0.25 \mathrm{~m}$ gap, as shown in Figure 8. The snaps of the arc were not synchronised between the different cases due to different dynamics. The different snaps in time enabled us to capture the impingement details for each case without the same time constraint. The arc jet was trapped inside the liquid metal. A wave travelled horizontally and it disturbed the surface more than the wave for the $0.25 \mathrm{~m}$ reference case. Another important effect was when the liquid metal entered the arc domain. The Lorentz force drifted the liquid metal upward toward the cathode (Figure 8, $0.358 \mathrm{~s}$ ). This effect led to more violent splashing afterward and a column of liquid metal was pushed downwards with a high speed. A large cavity was created (Figure 8, $1.022 \mathrm{~s}$ ). The initial impingement depth was less than that in the initial arc gap. This could be related to the shape of the impingement because the force was distributed horizontally due to a wider impingement.

When the arc gap increased to $0.3 \mathrm{~m}$, the arc became less stable and more chaotic movements were observed. The current and the thermal jet had to pass through a longer distance, implying the development of more wavy instability along the arc. This effect was observed initially but as time progressed the arc became more stable, as shown in Figure 9. The impingement depth was similar to the depth of the case with the $0.25 \mathrm{~m}$ arc gap. 

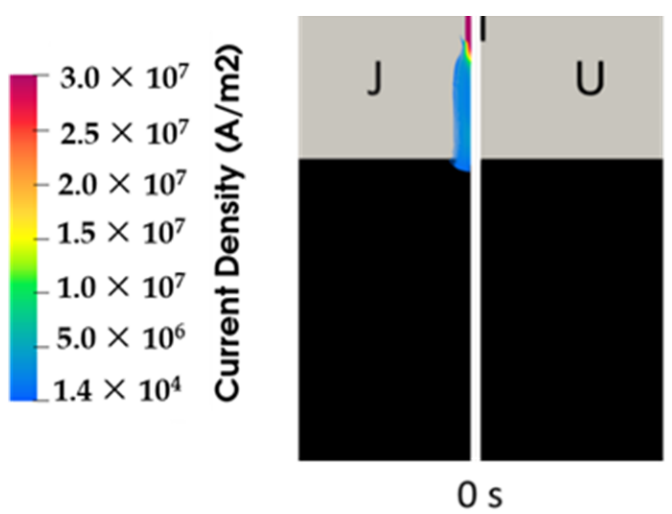

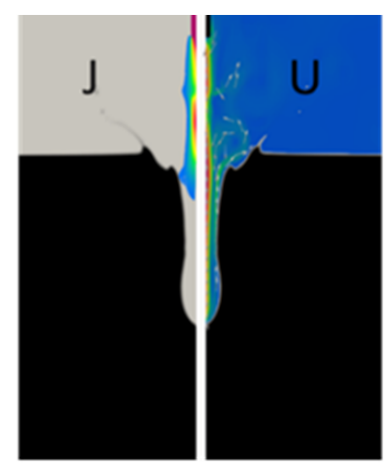

$0.15 \mathrm{~s}$

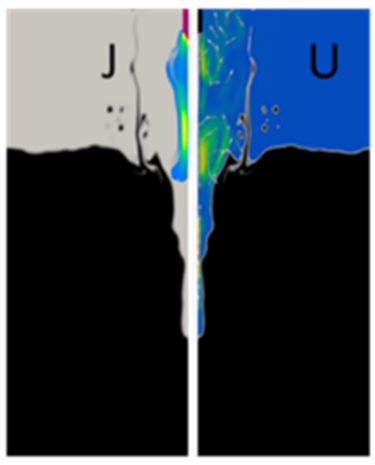

$1.022 \mathrm{~s}$
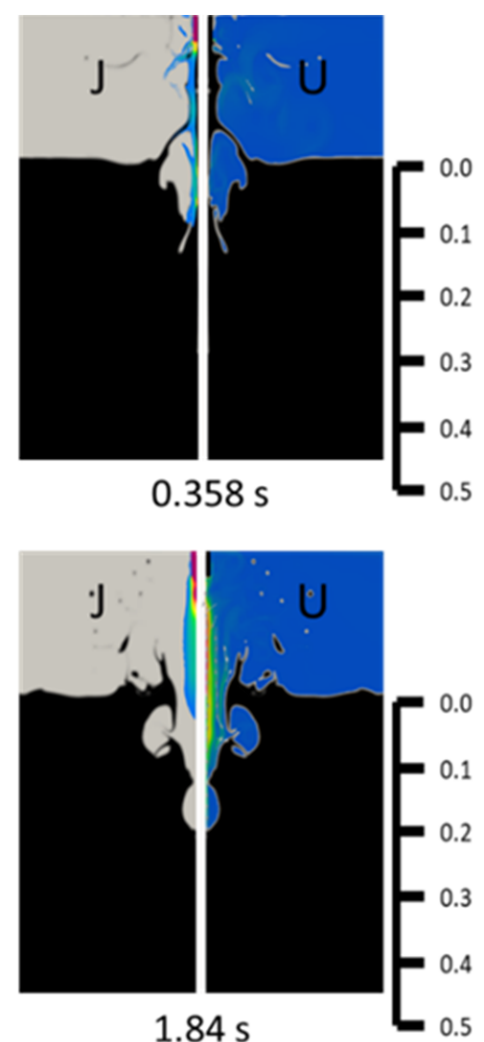

Figure 8. Liquid metal impingement by an arc jet for a $2.0 \times 10^{-1} \mathrm{~m}$ arc gap.

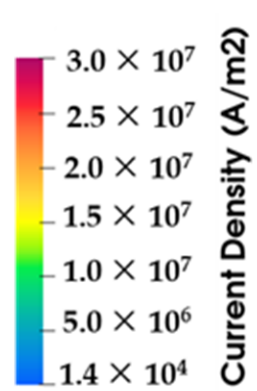

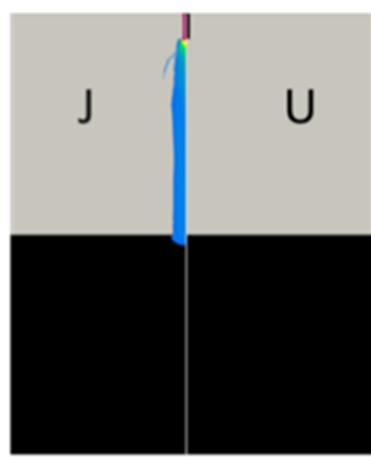

$\mathrm{Os}$

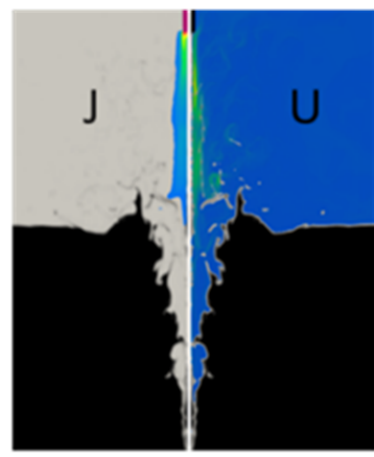

$0.524 \mathrm{~s}$

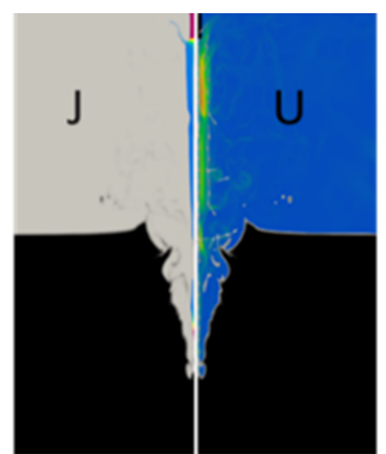

$0.154 \mathrm{~s}$

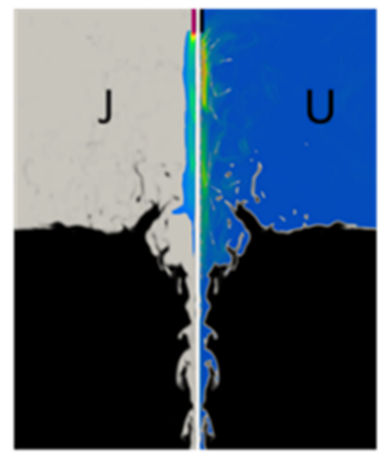

$0.83 \mathrm{~s}$
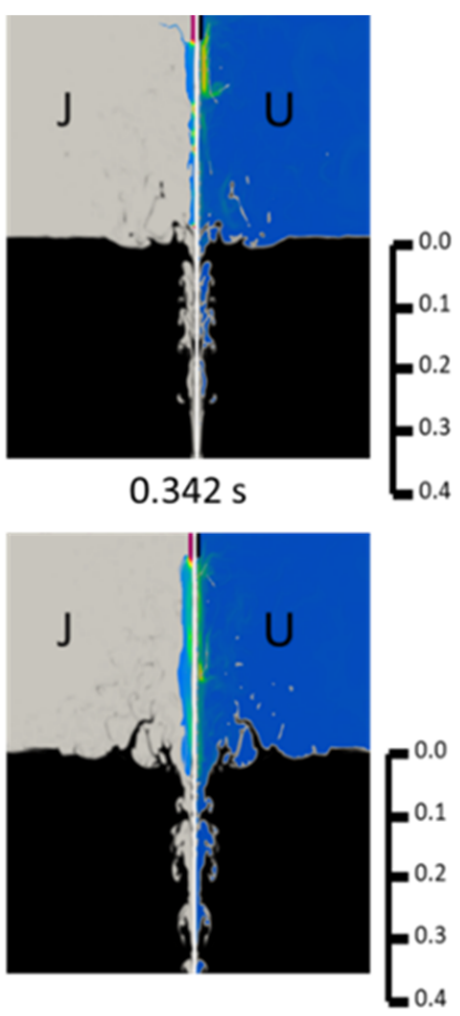

$0.93 \mathrm{~s}$

Figure 9. Liquid metal impingement by an arc jet for a $3.0 \times 10^{-1} \mathrm{~m}$ gap distance. 


\subsection{Effect of the Gas Density}

It is important to note that with a density of unity, a significant drop in the velocity of the gas inside the arc $(\mathrm{u}=140 \mathrm{~m} / \mathrm{s})$ was noticed whereas the stated velocity in the literatures is in the range of $10^{3} \mathrm{~m} / \mathrm{s}$. To assess the sensitivity of the variation of the density inside the arc due to a variation in the temperature and the importance of the value of the density, two additional simulations were performed. The only variable changed was the density of the gas, which was taken as $0.1 \mathrm{~kg} / \mathrm{m}^{3}$ and $0.01 \mathrm{~kg} / \mathrm{m}^{3}$.

The results showed that as the density lowered, the velocity of the plasma inside the arc increased significantly. When the density of the gas was equal to $0.01 \mathrm{~kg} / \mathrm{m}^{3}$, the speed reached the speed range in the literature of $10^{3} \mathrm{~m} / \mathrm{s}$. However, no effect on the overall impingement depth of the arc on the liquid metal was noticed. Figures 10 and 11 show the arc impingements for the different densities of the gas. Although the impingement depth was not significantly changed by the change in the density of the gas, the rate of droplet formation appeared to increase and droplets could reach a higher and further distance despite their smaller diameter. This could be explained by observing the average velocity profile for both cases. The average velocity was $450 \mathrm{~m} / \mathrm{s}$ for the density of $0.1 \mathrm{~kg} / \mathrm{m}^{3}$ and it was equal to $1.4 \times 10^{3} \mathrm{~m} / \mathrm{s}$ for the density of $0.01 \mathrm{~kg} / \mathrm{m}^{3}$.

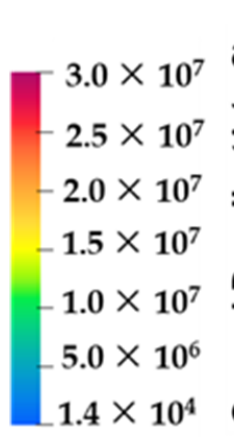

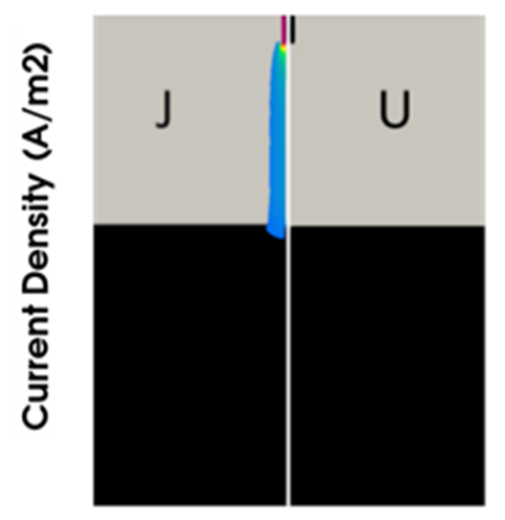

$0 \mathrm{~s}$

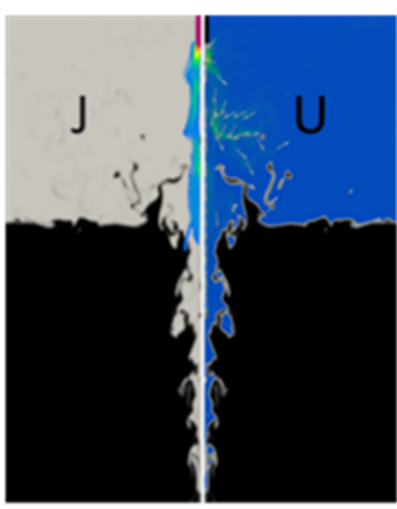

$0.58 \mathrm{~s}$

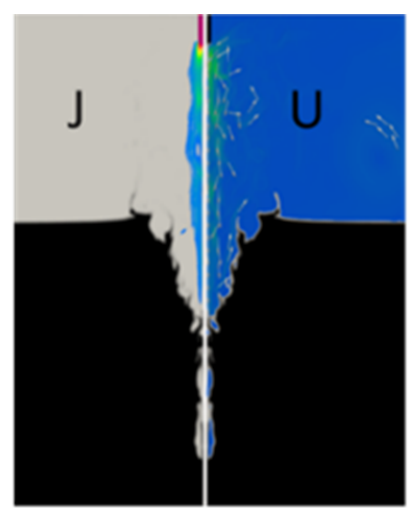

$0.156 \mathrm{~s}$

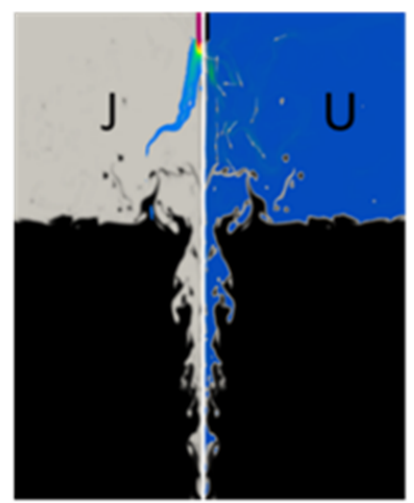

$0.604 \mathrm{~s}$

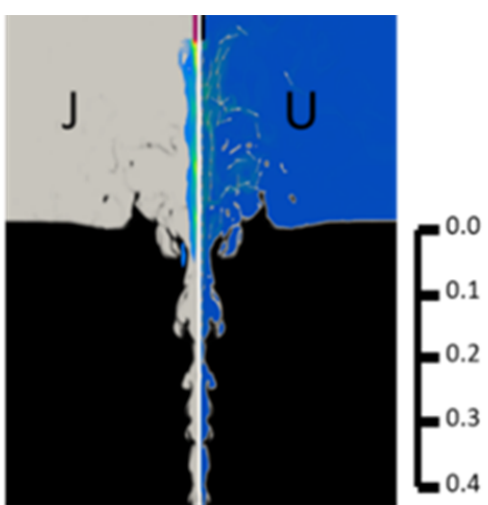

$0.4 \mathrm{~s}$

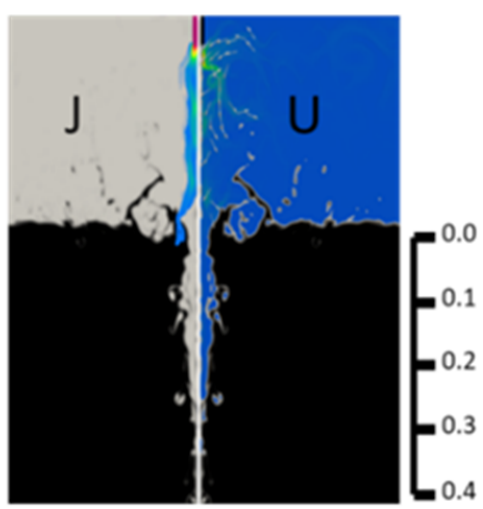

$0.8 \mathrm{~s}$

Figure 10. Liquid metal impingement by an arc jet for a gas density of $1.0 \times 10^{-1} \mathrm{~kg} / \mathrm{m}^{3}$. 


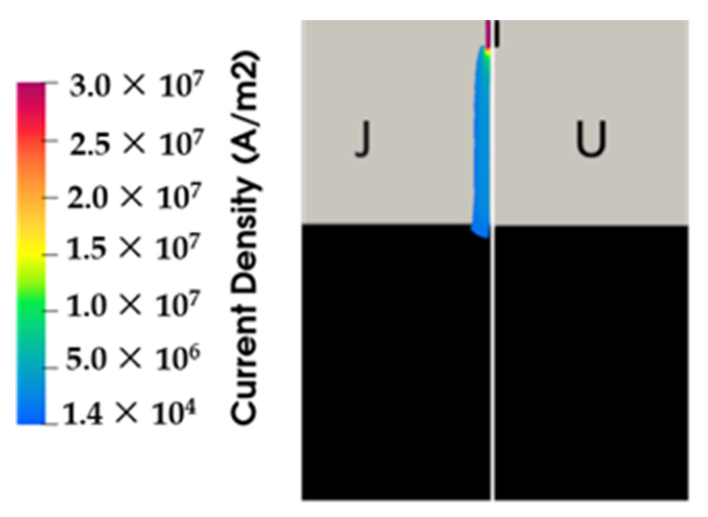

$0 \mathrm{~s}$

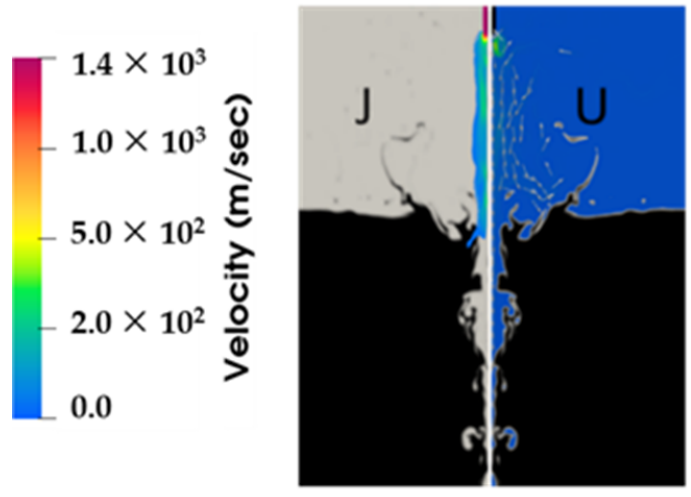

$0.39 \mathrm{~s}$

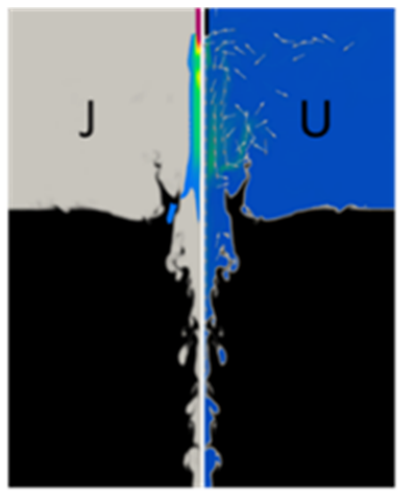

$0.242 \mathrm{~s}$

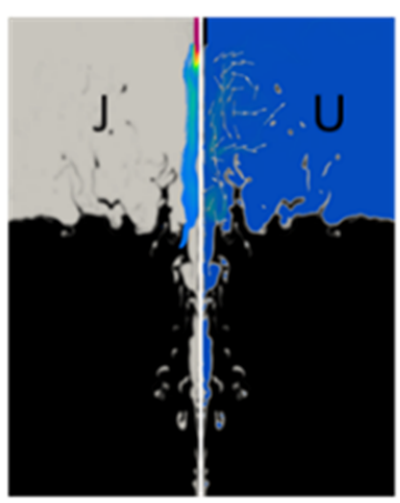

$0.744 \mathrm{~s}$

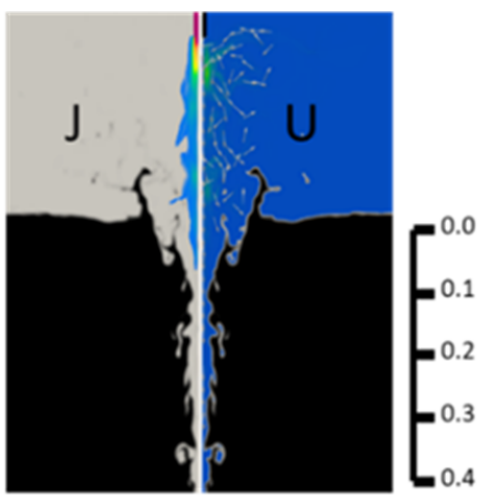

$0.344 \mathrm{~s}$

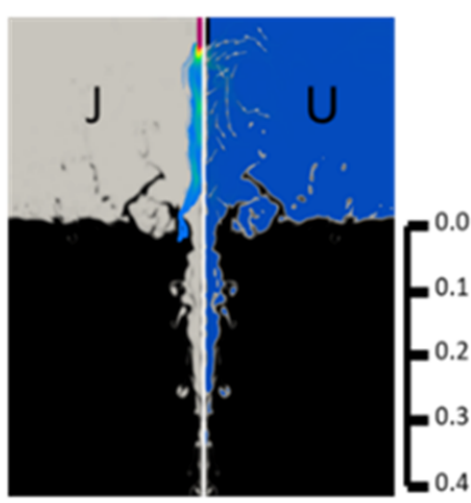

$0.844 \mathrm{~s}$

Figure 11. Liquid metal impingement by an arc jet for a gas density of $1 \times 10^{-2} \mathrm{~kg} / \mathrm{m}^{3}$.

\subsection{Effect of the Applied Current Magnitude}

In addition to the reference case, two Higher current values were considered. A higher applied current led to a deeper arc impingement. Figure 12 shows the extended area shown when a higher current was applied compared with the zoomed area shown in Figure 6. The current values that were applied are $20 \mathrm{kA}$ and $30 \mathrm{kA}$ (Figures 13 and 14, respectively). When a current of $20 \mathrm{kA}$ was applied, a larger arc diameter was observed; this was related to a larger cathode spot of $\sim 12 \mathrm{~mm}$ compared with that of the reference case (10 kA) of $\sim 8 \mathrm{~mm}$. When the jet reached the surface, a very large cavity formed, compared with the previous cases. The jet violently pushed the liquid metal in the horizontal and vertical directions. After $0.272 \mathrm{~s}$, the jet reached the bottom of the domain. As the time progressed, the impingement depth was maintained and the droplet splashing reached the top and side boundaries of the domain. Several waves also emerged on the surface and interacted with the droplets falling back into the bath. For the case of $30 \mathrm{kA}$, similar results appeared but with more powerful effects. Similarly, the arc radius was larger (cathode spot $\sim 15 \mathrm{~mm}$ ). The cavity was larger than that obtained in the case of $20 \mathrm{kA}$; thus, much more liquid was displaced. Once again, the jet easily exceeded a cavity depth of $0.71 \mathrm{~m}$ and reached the bottom. Due to the powerful jet, several gas bubbles were entrained inside the liquid metal. This led to a Rayleigh-Taylor instability. When these bubbles reached the surface, they caused very violent splashing similar to small explosions due to the very high density difference between the plasma and the liquid metal. The arc behaviour appeared to be very complex although it mainly followed the shortest path to the liquid metal. There appeared to be kink and sausage instabilities in the motion inside the plasma and the arc moved in a helical path. These phenomena were observed through experimental measurements by Reynolds [17]. 


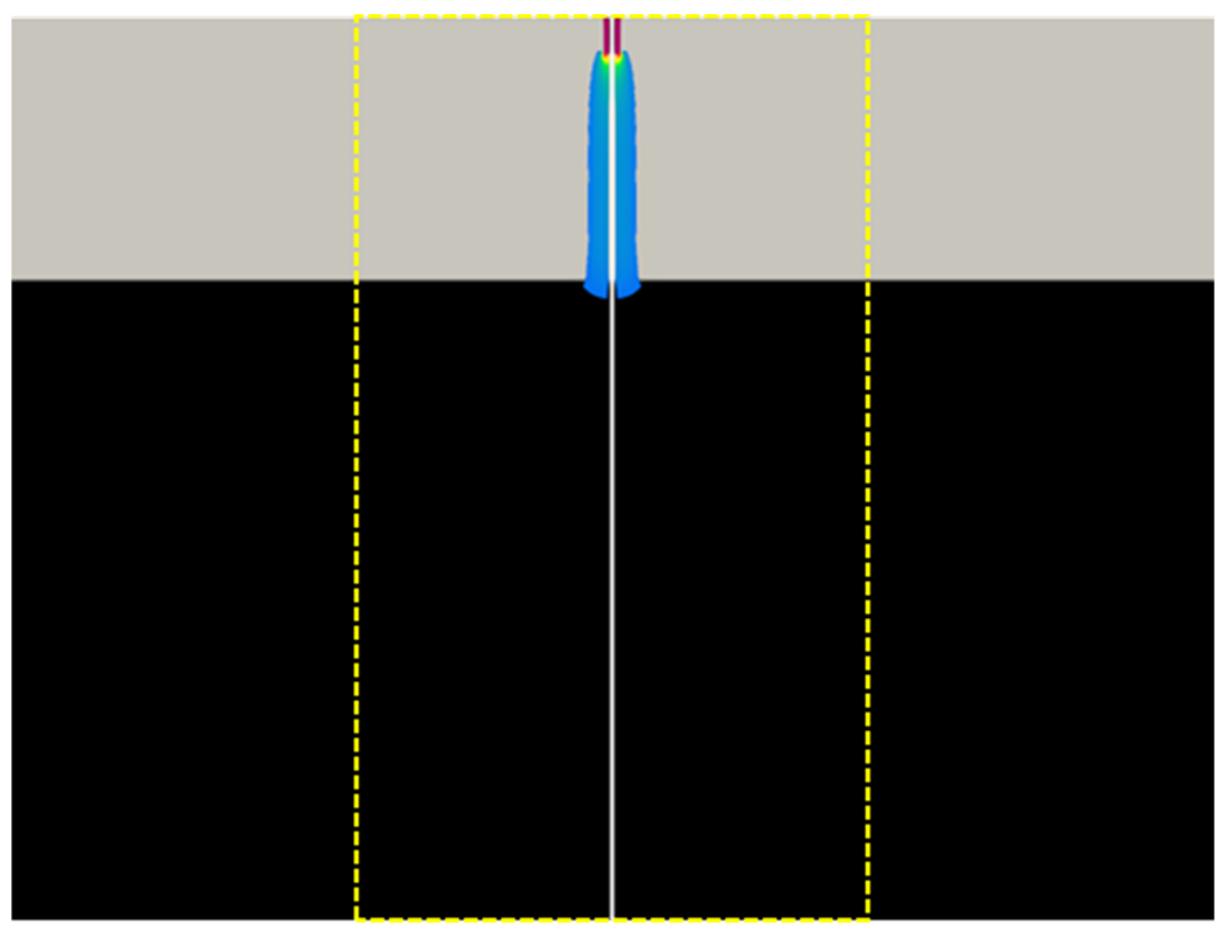

Figure 12. The zoomed domain is enlarged (yellow frame) due to a deeper arc impingement.

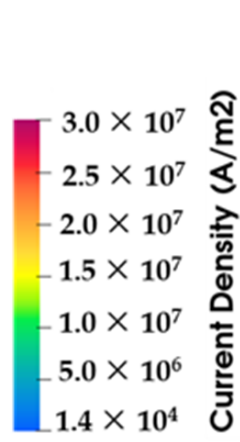

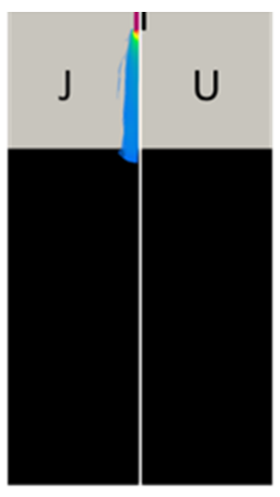

Os

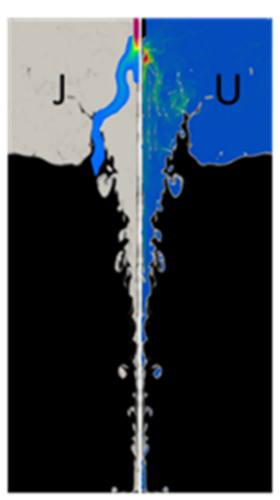

$0.372 \mathrm{~s}$

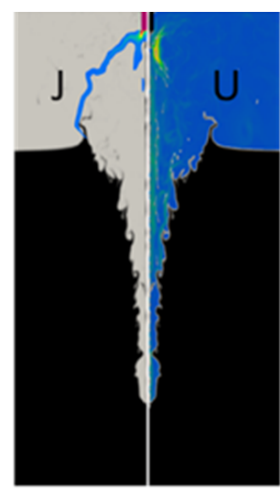

$0.182 \mathrm{~s}$

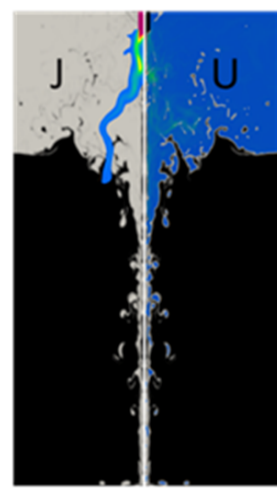

$0.536 \mathrm{~s}$

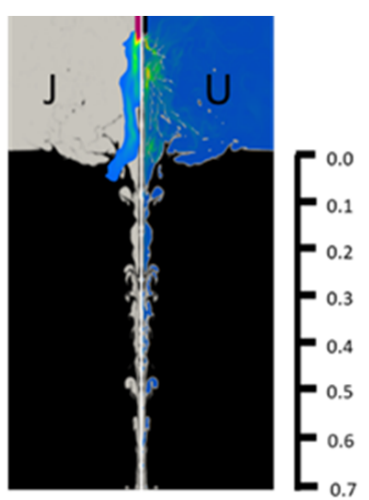

$0.272 \mathrm{~s}$

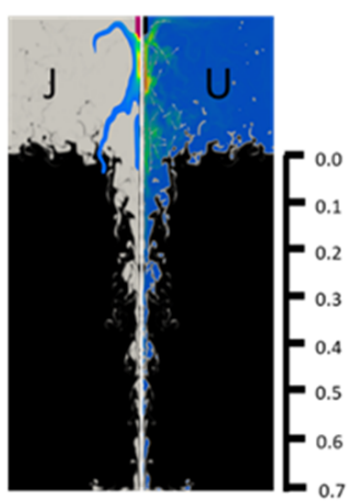

$0.932 \mathrm{~s}$

Figure 13. Liquid metal impingement by an arc jet for a total current of $2.0 \times 10^{1} \mathrm{kA}$. 


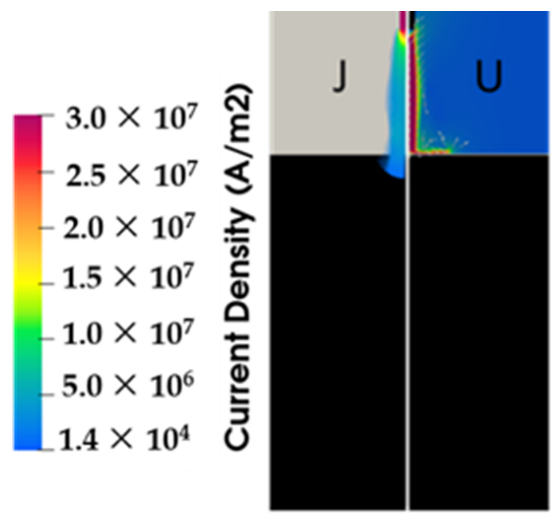

$0 \mathrm{~s}$

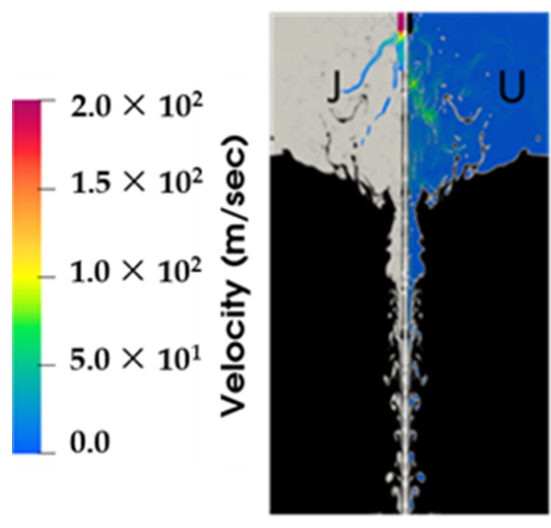

$0.58 \mathrm{~s}$

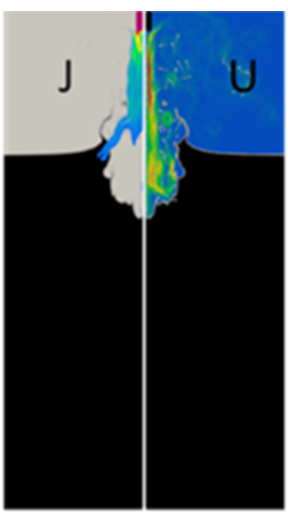

$0.046 \mathrm{~s}$

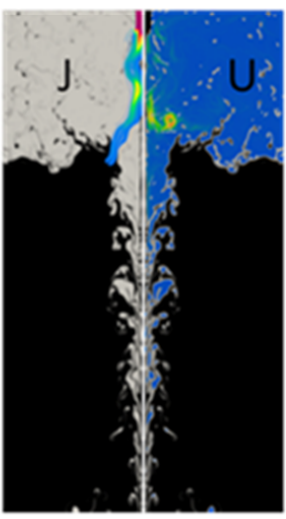

$0.604 \mathrm{~s}$

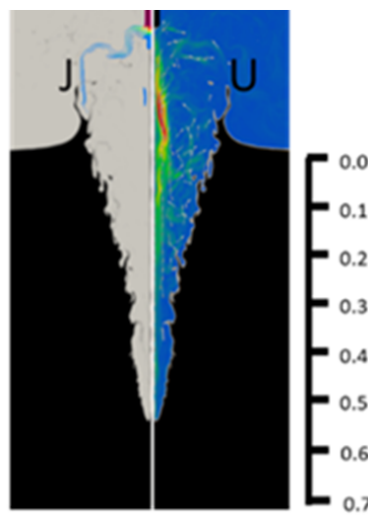

$0.136 \mathrm{~s}$

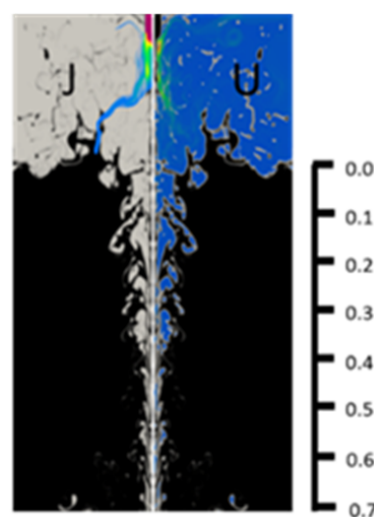

$0.8 \mathrm{~s}$

Figure 14. Liquid metal impingement by an arc jet for a total current of $3.0 \times 10^{1} \mathrm{kA}$.

The distance between the cathode and the arc attachment point with the conducting liquid was denoted by the actual arc length after the impingement (Table 3). For the reference case, the actual arc length was equal to $0.28 \mathrm{~m}$. As expected, when the initial arc gap decreased to $0.2 \mathrm{~m}$ the actual arc distance shrank to $0.22 \mathrm{~m}$ and for an arc gap of $0.3 \mathrm{~m}$, the length increased to $0.3 \mathrm{~m}$. When the applied current was increased to $20 \mathrm{kA}$, the arc distance increased to $0.3 \mathrm{~m}$ and $0.31 \mathrm{~m}$ when the applied current was increased to $30 \mathrm{kA}$. Similar to the arc impingement depth, the applied current was shown to be the most important factor.

Table 3. Parametric arc impingement results.

\begin{tabular}{cccccc}
\hline $\begin{array}{c}\text { Current } \\
(\mathbf{k A})\end{array}$ & Gap $(\mathbf{m})$ & $\begin{array}{c}\text { Gas Density } \\
\left(\mathbf{k g} / \mathbf{m}^{\mathbf{3}}\right)\end{array}$ & $\begin{array}{c}\text { Max Arc Jet } \\
\text { Velocity }(\mathbf{m} / \mathbf{s})\end{array}$ & $\begin{array}{c}\text { Cavity } \\
\text { Depth }(\mathbf{m})\end{array}$ & $\begin{array}{c}\text { Actual Arc } \\
\text { Length }(\mathbf{m})\end{array}$ \\
\hline 10 & 0.25 & 1 & $\approx 200$ & 0.5 & 0.28 \\
10 & 0.2 & 1 & $\approx 200$ & 0.4 & 0.22 \\
10 & 0.3 & 1 & $\approx 200$ & 0.5 & 0.3 \\
10 & 0.25 & 0.1 & $\approx 450$ & 0.5 & 0.28 \\
10 & 0.25 & 0.01 & $\approx 1400$ & 0.5 & 0.28 \\
20 & 0.25 & 1 & $\approx 200$ & $\geq 0.7$ & 0.3 \\
30 & 0.25 & 1 & $\approx 200$ & $\geq 0.7$ & 0.31 \\
\hline
\end{tabular}




\subsection{Discussion of the Thermal Field inside the Arc}

The temperature field is vital for the arc existence and propagation. The heat released through joule heating from the arc was the main source of energy in Equation (3). A high temperature ensured a high electrical conductivity for the current to flow. However, the time of simulation was minimal compared with the overall EAF process. Even though this period was enough to understand several important fluid and arc dynamics, it was not significant enough to affect the thermal distribution inside the conducting liquid. A detailed arc simulation was not convenient for studying the heat transfer inside the EAF. Considering the arc as a fixed cylindrical channel with constant boundary conditions including inlets and outlets for the gas and heat transfer on the circumferential area is more efficient and less computationally demanding [18].

\section{Conclusions}

A 2D axisymmetric two-phase model was developed to study the arc impingement inside an electric arc furnace. The obtained results attested that the proposed model could predict arc impingement phenomena. The assumptions made in this model could be justified as this model aimed to assess the effect of the arc jet on liquid metal and understand how the impingement affected the behaviour and stability of the arc. The main insights from this study are stated as follows.

The arc gap played an important role in the stability and the initial profile of the arc. A small gap induced a powerful splashing and drifted the metal inside the arc region, resulting in greater splashing as time progressed. For a larger gap, the stability of the arc reached a critical level at which the arc was extinguished. The cavity depth was not affected noticeably by the arc gap value.

The most important factor that linked the impingement depth to the mixing of the liquid metal was found to be the total applied current. The increase of the current value from $10 \mathrm{kA}$ to $20 \mathrm{kA}$ increased the penetration depth from $\sim 0.5 \mathrm{~m}$ to $>0.71 \mathrm{~m}$ (Table 3 ) and reached the bottom boundary. Rayleigh instabilities were created due to the entrapment of gas bubbles inside the liquid metal. These bubbles led to small explosions and powerful splashing when they reached the liquid surface due to a high density difference.

The density of the plasma did not affect the level of the impingement depth but the distribution of the droplets and their size were affected. When the density decreased, the splashing rate increased qualitatively; this was due to a higher arc velocity. The velocity increased as the density decreased. However, the rate of velocity change was not linearly proportional to 1 over density. The rate validated the conservation of momentum $\rho u^{2}=$ const. Moreover, the actual arc length (similar to the impingement depth) was not affected by the density value, which again enforced the validity of the constant density assumption. The obtained arc length reconfirmed that the applied current was the chief factor in the arc impingement. This explained the obtained results for the unvarying depth of the impingement and validated the use of a constant density for less computational effort.

Two ideas that could improve the modelling in future are the consideration of the compressibility of the plasma and the freedom of the cathode spot motion although these adjustments impose more technical constraints and the need of a very high computational power as a result of the necessity to drastically decrease the time step. A further step to take the model forward is the development of a 3D model. This step could enhance our understanding of the arc behaviour, giving the arc freedom to be deflected and non-symmetrical.

Author Contributions: Conceptualization, A.K., investigation, M.A.-N., M.W. and H.B.; supervision, A.I., M.G. and C.R.; visualization, M.A.-N. and A.L.; writing-original draft, M.A.-N. and A.K.; writing-review and editing, C.P., G.H. and M.G. All authors have read and agreed to the published version of the manuscript. 
Funding: This research was funded by the Austrian Federal Ministry of Economy, Family and Youth and the National Foundation for Research, Technology and Development within the framework of the Christian-Doppler Laboratory for Metallurgical Applications of Magnetohydrodynamics (Abdellah Kharicha).

Institutional Review Board Statement: Not applicable.

Informed Consent Statement: Not applicable.

Data Availability Statement: Data presented in this article is available on request from the corresponding author.

Acknowledgments: Abdellah Kharicha and Mohamad Al-Nasser acknowledges financial support from the Austrian Federal Ministry of Economy, Family and Youth and the National Foundation for Research, Technology and Development within the framework of the Christian-Doppler Laboratory for Metallurgical Applications of Magnetohydrodynamics.

Conflicts of Interest: The authors declare no conflict of interest.

\section{Abbreviations}

$\begin{array}{lll}\text { Symbol } & \text { Name } & \text { Unit } \\ \rho & \text { Density } & \mathrm{Kg} / \mathrm{m}^{3} \\ U & \text { Velocity } & \mathrm{m} / \mathrm{s} \\ p & \text { Pressure } & \mathrm{N} / \mathrm{m}^{2} \\ \mu & \text { Kinetic viscosity } & \mathrm{m}^{2} / \mathrm{s} \\ g & \text { Gravitational acceleration } & \mathrm{Nm}^{2} / \mathrm{kg}^{2} \\ t & \text { Time } & \mathrm{s} \\ T & \text { Temperature } & \mathrm{K} \\ c p & \text { Specific heat } & \mathrm{J} / \mathrm{k} \cdot \mathrm{kg} \\ K & \text { Thermal conductivity } & \mathrm{W} / \mathrm{m} \cdot \mathrm{K} \\ B & \text { Magnetic field } & \mathrm{T} \\ J & \text { Current density } & \mathrm{A} / \mathrm{m}^{2} \\ \mu_{0} & \text { Vacuum permeability } & \mathrm{H} / \mathrm{m}\end{array}$

\section{References}

1. Jones, R.T.; Reynolds, Q.G.; Curr, T.R.; Sager, D. Some myths about DC arc furnaces. J. South. Afr. Inst. Min. Metall. 2011, 111, 665-674.

2. Szekely, J.; McKelliget, J.; Choudhary, M. Heat-transfer fluid flow and bath circulation in electric-arc furnaces and DC plasma furnaces. Ironmak. Steelmak. 1983, 10, 169-179.

3. Bowman, B.; Krüger, K. Arc Furnace Physics; Verlag Stahleisen: Düsseldorf, Germany, 2009; pp. 176-190.

4. Ushio, M.; Szekely, J.; Chang, C.W. Mathematical modelling of flow field and heat transfer in high-current arc discharge. Ironmak. Steelmak. 1981, 8, 279-286.

5. Alexis, J.; Ramirez, M.; Trapaga, G.; Jönsson, P. Modeling of a DC electric arc furnace-heat transfer from the arc. ISIJ Int. 2000, 40, 1089-1097. [CrossRef]

6. Ramírez, M.; Alexis, J.; Trapaga, G.; Jönsson, P.; Mckelliget, J. Modeling of a DC electric arc furnace-Mixing in the bath. ISIJ Int. 2001, 41, 1146-1155. [CrossRef]

7. Kazak, O. Numerical modelling of electrovortex and heat flows in dc electric arc furnace with cooling bottom electrode. Heat Mass Transf. 2014, 50, 685-692. [CrossRef]

8. Reynolds, Q.G. Application of multiphase computational fluid dynamics to the plasma arc impingement problem in DC furnaces. In Proceedings of the 9th South African Conference on Computational and Applied Mechanics, Somerset West, South Africa, 14-16 January 2014; pp. 14-16.

9. Klementyeva, I.B.; Pinchuk, M.E. Parameters of electrical discharges with liquid metal electrode. J. Phys. Conf. Ser. 2015, 653, 012150. [CrossRef]

10. Reynolds, Q. Computational Modeling of Arc-Slag Interaction in DC Furnaces. JOM 2017, 69, 351-357. [CrossRef]

11. Adib, M.; Ehteram, M.A.; Tabrizi, H.B. Numerical and experimental study of oscillatory behavior of liquid surface agitated by high-speed gas jet. Appl. Math. Model. 2018, 62, 510-525. [CrossRef]

12. Ansys Fluent Software; Version 14.5; 275 Technology Drive Inc.: Canonsburg, PA, USA, 2011.

13. Morris, J.C.; Bach, G.R.; Krey, R.U.; Liebermann, R.W.; Yos, J.M. Continuum radiated power for high-temperature air and its components. AIAA J. 1966, 4, 1223-1226. [CrossRef]

14. Boulos, M.I.; Fauchais, P.; Pfender, E. Thermal Plasmas: Fundamentals and Applications; Springer: New York, NY, USA, 2013. 
15. McKelliget, J.W.; Szekely, J. A mathematical model of the cathode region of a high intensity carbon arc. J. Phys. D Appl. Phys. 1983, 16, 1007. [CrossRef]

16. Jordan, G.R.; Bowman, B.; Wakelam, D. Electrical and photographic measurements of high-power arcs. J. Phys. D Appl. Phys. 1970, 3, 1089. [CrossRef]

17. Ramírez, M.A. Mathematical Modeling of DC Electric Arc Furnace Operations. Ph.D. Thesis, Massachusetts Institute of Technology, Cambridge, MA, USA, 2000.

18. Gruber, J.C.; Echterhof, T.; Pfeifer, H. Investigation on the influence of the arc region on heat and mass transport in an EAF freeboard using numerical modeling. Steel Res. Int. 2016, 87, 15-28. [CrossRef] 